\title{
Utilising Building Information Models in Facility Maintenance and Operations
}

\author{
ESA HALMETOJA ${ }^{1}$ \\ Natalija LEPKOVA ${ }^{2}$
}

\begin{abstract}
Utilising the digital capital of buildings, including building information modelling (BIM), is crucial for building owners from the perspective of high-level maintenance. This case study concerns a company in which building information models are received as files complying with the Industry Foundation Classes (IFC) standard. An analysis of the information content of the IFC files was performed to investigate whether the files, which were generated in a construction project using traditional procedures, contained relevant information for maintenance. The critical needs were evaluated based on the aspects highlighted in an online survey. As a result, essential content requirements for BIM are presented for facility maintenance and operations (FMO). It has been shown that existing building information models cannot close the information gap from a facility maintenance perspective. Still, they have significant potential due to their ability to contain technical information and provide a graphical representation. With information exchange requirements (IERs), a great deal of progress could be made by utilising BIM for FMO. A property service company's capabilities must also be evolved before the benefits of digital capital can be reaped. This paper provides insights for developing the information content of computerised maintenance management systems (CMMS) and demonstrates the crucial need to harmonise them using BIM. Finally, as a new use case for BIM, this paper presents an operations and maintenance model (OMM).
\end{abstract}

Keywords: Operations and maintenance model, property maintenance, building information models in facility maintenance and operations.

\section{INTRODUCTION}

Facility maintenance and operations (FMO) contains two main task areas: (1) the care and maintenance of building and technical systems (including the repair and replacement of technical systems), and (2) care and maintenance of outdoor areas [1]. In this case study,

Note:

- This paper was received on June 5, 2020 and accepted for publication by the Editorial Board on August 13, 2021.

- Discussions on this paper will be accepted by November 30, 2022.

- https://doi.org/10.18400/tekderg.748397

1 Senate Properties, Maintenance Unit, Helsinki, Finland esa.halmetoja@senaatti.fi - https://orcid.org/0000-0002-0631-273X

2 Department of Construction Management and Real Estate, Vilnius Gediminas Technical University, Vilnius, Lithuania - Natalija.Lepkova@vilniustech.lt - https://orcid.org/0000-0002-9760-1747 
FMO is considered to be an activity that continually keeps a building in good shape, uses the building's technology appropriately, optimises energy use, and ensures that occurrences and deviations do not cause damage or become a danger to people, equipment or structures.

In the last twenty years, digitalisation has appeared and big data has emerged, but the operation models of FMO are still old-fashioned and integrations between systems are inadequate. Digitalisation also plays a crucial role in the design of buildings and the management of construction projects. Building information models have been commonplace in significant construction projects $[2,3,4]$.

The specific objective of this case study is to investigate whether it is possible to digitalise facility management (FM) by introducing BIM in post-construction and to discover what the crucial requirements are. This study focuses on the practical FMO processes of the principal company, and other use cases are excluded. The primary research questions are:

- Could BIM operate as an information source for FMO?

- What are the crucial requirements for BIM in FMO?

Because the case company's aim is to introduce BIM to post-construction use, as has been presented in the related standards, it is crucial to investigate existing BIM files to validate their usability in FM. It is also essential to define what information must be added to BIM to enable its post-construction use.

\section{THEORETICAL BACKGROUND}

The term BIM is used to describe a building information model, building modelling, and technology related to building modelling. For the sake of clarity, the explanatory terms modelling, technology or process are used in this paper. BIM is an evolving approach concerning digital information in facilities [5]. Besides the geometry and structures, BIM includes definitions about the building's other elements, such as heat, ventilation and air conditioning (HVAC) equipment, spaces, zones, furniture and specific properties [6]. The National BIM Standard of the United States (2015) describes BIM as a digital presentation of the physical and functional characteristics of a facility that explains how a building is conceived, designed, constructed and operated [7].

Krygiel et al. (2008) noted that BIM allows lifetime information management, promotes sustainable development, and enables optimal service life and environmentally friendly construction [8]. BIM applications have also been used increasingly to support sustainability in the construction industry [9]. At present, BIM technology is widely used in construction projects for building site management, quality, time management and financial control $[10,11]$. BIM modelling is essentially a software-facilitated process used by architects, engineers and contractors (AEC designers) in the construction industry [12].

According to Azhar et al. (2015), BIM modelling supports the real estate business and the high-level management of the investment process [13]. Typically, as-built BIM is transferred to a client after a construction project for post-construction use. BIM can also generate and maintain the information produced during the whole life cycle of a building project - from design to maintenance - and can be applied to various fields $[14,15]$. 
The strength of BIM modelling is the ability to store, synthesise and visualise both semantic and relational information along with geometric information. The geometric information identifies the location, while relational information contextualises the work order within the building (at the room, system or equipment level), and semantic information contains the key content [16]. A few examples in the related literature are presented in which data transferred from BIM for maintenance are used [11, 17, 18]. For example, Chen et al. (2018) proposed a facility maintenance management framework based on BIM and facility management systems that can provide the automatic scheduling of maintenance work orders in order to enhance good decision-making in facility maintenance management [17]. Because BIM software is not intended for FM functions, priority should be given to finding solutions for transferring semantic data from BIM for use by FM software.

Ustinovičius et al. (2018) presented the conceptual model of BIM-based design and refurbishment [19]. The proposed new approach presented in this model creates a knowledgebased decision-making environment for refurbishment strategies and quality control, thus creating the preconditions to bridge the gap between expected and actual energy performance. Heaton et al. (2019) presented a methodology that enables the extraction of BIM-related data directly from a model into a relational database, for integration with existing asset management systems [20]. The article presented a case study which demonstrates that if BIM is designed from the start with consideration for operations and maintenance requirements, it can be exploited for development into an asset information model.

The Industry Foundation Classes (IFC) standard is an XML-based international ISO/PAS 16739 (2018) construction industry standard for the transfer of object-oriented data from one computer system to another in BIM [21]. It is used to transfer design data between CAD systems and from design software to various analysis and production software. The IFC process only transfers $3 \mathrm{D}$ geometry and parameters. An IFC file is thus a kind of tabular description of the contents of BIM.

It is standard practice for AEC designers to adhere to the coverage of plans defined by the subscriber. Therefore, in order to include the information required in the FM, it is essential to define information exchange requirements (ER or IER), as well as principles of data management, shared product libraries, etc. at the contract stage.

The Construction Operations Building Information Exchange (COBie) standard is an international standard relating to managed asset information, including space and equipment. It is closely associated with BIM modelling approaches to the design, construction and management of built assets [22]. COBie is still a relevant standard for delivering standardised data in aid of asset management cost reductions. However, additional rules are required, because COBie does not provide details on what information is to be provided when, and by whom [23].

FM is a form of asset management that is concerned with the successful and profitable maintenance, operation and monitoring of buildings or properties [24]. FM presents an integrated approach to maintaining, improving and adapting an organisation's buildings in order to promote a fertile environment that supports an organisation's primary objectives [25, 26]. FM encompasses the workplace, facility, support services, property, corporate real estate and infrastructure [27]. 
The ISO 41011:2017 standard defines FM as an organisational function that integrates people, places and processes within the built environment in order to improve the quality of life for people and the productivity of the core business [28]. FM covers two primary areas: space and infrastructure (including planning, programming, design, construction, leasing, occupancy, maintenance, renovating, energy, the environment, waste, workplace design, furniture, moving and cleaning), and people and the organisation (including reception, catering, hospitality, ICT, information technology (IT), office supplies, travel, car parking, accounting and marketing). On a general level, FM thus aims to provide safe, healthy and efficient work environments for clients [29].

ISO 19650:2018 series 1 describes and defines information management across the whole life cycle of an asset [30]. To support this, there needs to be close links with the approaches used for asset and project management, and for organisational management. ISO 19650-1 allows for an inexperienced appointing party to seek assistance with completing its information management activities [31].

BIM-based application initiatives in FM can be found in newly published research papers. By linking the BIM-based structural elements with FM work information, BIM and FM databases can be integrated for easy information accessibility and utilisation. Kim et al. (2018) proposed an approach to effectively manage BIM-based FM information by linking the BIM-based building elements and FM work information in an FM system database [32]. The authors presented a web-based FM information system that semantically links BIM data to relevant historical work records. Chen et al. (2020) developed a specification-compliant FM system based on BIM using the Lingxia tunnel in Wenzhou, China, as a testbed [33]. The application of the system in the mountainous tunnels demonstrates the feasibility and benefits of BIM-based FM related to productivity improvement.

Ustinovičius et al. (2017) noted that BIM modelling allows them to analyse the current situation, solving problems with information management using team-based collaborations and integrated project delivery [19, 54]. Motawa and Almarshad (2013) developed an integrated system to capture information about and knowledge of building maintenance operations when maintenance is carried out and afterwards in order to understand how a building deteriorates, and to support preventive/corrective maintenance decisions [34]. Halmetoja (2019) presented a way to combine the information content of BIM and field data on the same platform to provide real-time information for improving FM operations [35].

Kang and Choi (2015) showed that BIM modelling could enhance the FM process by expediting tasks and reducing time loss [36]. Aziz et al. (2016) underlined that using BIM for FM could lead to a reduction of operational costs; less time spent on decision-making; a better documentation procedure; greater collaboration and more work flexibility [37]. The research by Pishdad-Bozorgi et al. (2018) analysed BIM for FM case studies presented in the literature by different authors from 2010 to 2016 [38]. By using a project example, the authors showed the importance of the implementation of FM-enabled BIM. Gao and PishdadBozorgi (2019) studied academic articles, industry reports and guidelines pertaining to the use of BIM to improve selected facility O\&M activities, including maintenance and repair, emergency management, energy management, change/relocation management and security [39]. Content analysis results showed that research on using BIM for O\&M is still in the early stages and most of the current research has focused on energy management. Wong et al. (2018) analysed the digitalisation process in facility management. The authors analysed 120 
academic journal papers, conference proceedings and other technical notes published on the subject (BIM concept, combined geographic information systems (GIS) and BIM technology, IoT, reality capture technology with photogrammetry and laser scanning tools application for FM) mainly between 2004 and 2017 [40]. Araszkiewicz (2017) presented the results of the latest research related to the application of digitisation in facility management based on a literature review from 2010 to 2016. The article investigated the potential application of BIM for data integration for the building life cycle, providing information for facility management and maintenance, as well as FM for smart buildings [41].

Applying BIM for FM requires changes within organisations. Cavka et al. (2017) developed a methodology for understanding owner requirements and identifying BIM-related information [42]. Their method covers a lot of the requirements for BIM-enabled asset management and leads to significant changes in workflows.

According to the literature, many FM applications have adopted BIM technology and provide functions for building maintenance, but knowledge management is not usually offered. For example, lessons learnt from investigations into the causes of failure, or the consequences of selecting a specific method of maintenance, and the ripple effects on other building elements have not been thoroughly researched. The current article describes how to enrich the content of the models so that they can be utilised in FMO. This was not reported in the analysed literature.

\section{CASE STUDY DESCRIPTION}

The principal company is a sizeable property-owning company that is known as a pioneer and leader in the use of digital tools for FMO. For example, their CMMS has been used for as long as they have existed. The company owns about 9,200 buildings, covering approximately six million square metres and serving nearly 55,000 occupants daily. The company is also a pioneer in utilising BIM in design and construction. Similar material is rarely found in other companies when researching the FMO field. The company uses smart building technologies and aims to introduce a digital twin of each building in everyday use in four years. This study reveals the current state of the digital material and shows how it should be developed to achieve this goal.

As BIM for FM is an entirely new use case, it is not relevant to assume that previous BIM files will comprehensively contain FM information, especially insofar as they differ from the information needed for a construction project. However, it is crucial to investigate whether existing BIM can be utilised in FM or whether they need to be regenerated entirely for this purpose.

In this study, we exploited the task lists and device lists of the CMMS. We were permitted to use the online repository system of the case company. The total number of BIM files amounted to over 10,000, from which 15 buildings with 238 BIM files produced using a computer-aided design (CAD) modelling program were chosen for analysis. These buildings were similar regarding the CMMS and scope of BIM. The target was to explore the compatibility of the CMMS and BIM using traditional analysis tools. 
Three types of buildings were involved: office buildings, which included standard offices (nine buildings), education buildings for schools (three buildings), and special premises, including research and laboratory buildings (three buildings).

Besides exploiting the available files, we used an online survey to investigate the availability and quality of crucial information. Further, if a gap in the information needed for property maintenance occurred, we examined whether BIM could close the gap. The accordance of the FMO service provider's and the property owner's values was also assessed, and the ability of the CMMS to support this target was investigated. A web link to the online survey was emailed to 479 janitors, supervisors and property service bidders working in the five largest property service companies in Finland. About 23,000 employees work for these companies in the Finnish property service market. All the respondents had working experience of the principal company's properties.

\section{METHODOLOGY}

The current BIM Modelling guidelines were studied, and the FMO needs were observed using relevant literature. Gaps in the current research were detected. The information content of current IFC files were analysed to find out whether they contained useful data for FM. The CMMS device lists and task lists were also explored. The FMO information requirements, quality and availability were examined using an online survey. Finally, the essentials of the research were conceptualised, and conclusions were drawn using qualitative analysis.

\section{The online survey}

The purpose of the online survey was a) to determine the information requirements, qualifications and availability for day-to-day work of the personnel, and b) to map the personnel's BIM know-how. Those issues are crucial to evaluating the current availability of information and considering how to utilise BIM in property maintenance work.

An online survey was selected as a method because it enables remote access to individuals. It can also reach challenging-to-contact participants and can enable automated data collection $[43,44,45]$. Further, the author cannot influence the responder during the survey through their attitudes or behaviour [46].

The questions were compiled with the principal company's maintenance team and tested in advance. The questions are based on CMMS task lists. The questions were designed to be unambiguous so that they were easy to answer regardless of the educational background of the respondents, and did not contain demanding terminology. The questions reflected the general values of the real estate and construction industries and were designed to reveal correlations with the service providers, who provide property services for the case company. The questions about BIM were hypothetical because BIM was not yet in use in the case company. The questionnaire was designed to enable the researchers to develop proposals to introduce BIM for a property owner who already owns a significant number of building information models and who is continually ordering them.

Scores were calculated using the weighted average method, according to ISO Standard ISO 41011:2017 Facility Management - Part 7: Guidelines for Performance Benchmarking [48]. A five-step Likert scale was used, wherein the minimum score was 0 and the maximum rating 
was 5 [49]. The same score was used multiple times. Every question had the option for a textual comment.

\section{The empirical analysis of BIM and CMMS}

Empirical research methods are usually associated with inductive approaches, which are based on empirical evidence [47,50]. According to Ghauri et al. (2002), "The research design is the overall plan for connecting the conceptual research problems to pertinent (and achievable) empirical research." [51] The purpose of empirical research is to obtain research results by making actual observations of the subject and analysing and measuring them. In empirical research, concrete and aggregated research material serves as the starting point for research [52].

In the empirical analysis, the information content of the BIM files was explored, and an analysis of the device lists and task lists of the CMMS was made. The online survey answers were utilised in order to specify the content analysis of the building information models. The tool used was Microsoft Excel ${ }^{\circledR}$, and the data was collected manually by using the Solibri model checker (SMC).

We decided to examine the current IFC files instead of the original CAD files for better readability. IFC files are compatible with all standard analytics applications, and a licence for the initial modelling application is not needed. Thus, differences in the models caused by the design software can be excluded. The same applies to the architectural models, structural models, and mechanical, electrical and plumbing (MEP) models [53]. The IFC format is the most practical when utilising the information content of BIM for external use. The central idea was to investigate the usability of the content of existing IFC files. The conclusions take into account that when creating these files, the subscriber had not submitted any content requirements for the information required in the FM.

Fifteen buildings were chosen for the comparison process. The criteria for selecting buildings for the study were:

- $\quad$ the model should cover the entire property

- $\quad$ MEP models should exist

- $\quad$ the models should cover the same area as the device list of the CMMS

The content of the architectural model was based on the authors' view of the required information, which was evaluated according to the results of the online survey and reviewed by FM-related professionals. The following issues were examined in order to determine whether or not there was data on them:

a. The total area and volume of a building

b. The borders (spatial separations) of users in the multi-user buildings

c. Architectural space objects

d. Emergency exits and hauling routes

e. Care and maintenance instructions

f. The technical details of structures and surfaces 
The verification of the content of the MEP model was based on CMMS task lists and made in the online survey. The following issues were examined in order to determine whether they exist or not:
a. Pipes, ducts and cable ladders
b. Equipment to maintain and/or indicate alarms (compared to the CMMS device list)
c. The technical details of the HVAC equipment (including capacities and set-points)
d. Fire and automatic air volume control dampers, and shut-off and automatic valves (compared to the CMMS device list)
e. The operation areas of the HVAC systems

The buildings were categorised by their use/purpose (office/education/special premises), and their gross floor area (GFA) and gross volume (GV) were described. The date of the IFC file was also recorded.

\section{RESULTS}

\section{Online survey}

In the online survey, a total of 479 people were contacted, and 161 replies were received (33.6\% reply rate). The majority of the respondents were men (96\%), and the majority were aged 31-40 (58\%). Eighteen per cent were under 30 years of age, and 12\% were over 60 years of age. A total of $44 \%$ had more than 20 years of work experience. The next largest group had $11-15$ years of work experience (23\%), followed by $6-10$ years $(20 \%)$ and $16-20$ years $(18 \%)$. About $12 \%$ had less than five years of work experience. The distribution of occupations among the respondents was as follows: $55 \%$ were janitors or mechanics; $13 \%$ were foremen or managers; $15 \%$ were technical managers or supervisors; $4 \%$ were directors or chief officers; $3 \%$ were bidders or controllers; and $2 \%$ were the space user's representatives. The remaining $9 \%$ were mostly service managers and system specialists. The statistical review is presented in Table 1.

In the first question, we asked about the significance of the features of a building in general. The principal company is aiming to improve the efficiency of the space users' work and hopes to manage life cycle costs by implementing technically advanced (smart) buildings. Other essential features are safety and security, energy efficiency, healthiness, value retainability and a good user experience. Additionally, the ease of care and maintenance and the economic viability for the service company are important when pursuing good maintainability.

Figure 1 presents the results of the first question. According to the responses, healthiness was the most highly valued feature (4.86/5), followed by safety and security $(4.86 / 5)$, and then by the building's ability to retain its value $(4.63 / 5)$. The fourth most valued feature was the provision of a good user experience (4.54/5); and energy efficiency was only fifth (4.46/5). The ease of maintenance (4.30/5) and economic viability for the service company (4.04/5) were the sixth and seventh most valued features. The technical intelligence of the building was the least valued feature (3.67/5). 
Table 1 - Distribution of respondents according to different features.

\begin{tabular}{|c|c|}
\hline $\begin{array}{l}\text { Distribution of } \\
\text { respondents }\end{array}$ & Description \\
\hline $\begin{array}{l}\text { Distribution of } \\
\text { respondents to } \\
\text { professions }\end{array}$ & $\begin{array}{l}\text { Janitors or mechanics }(58 \%) \text {; various supervisors and } \\
\text { managers }(28.8 \%) \text {. The smallest respondent group is managers } \\
\text { working for space user organisations }(2.6 \%) \text {. }\end{array}$ \\
\hline $\begin{array}{l}\text { Distribution of } \\
\text { respondents to } \\
\text { education }\end{array}$ & $\begin{array}{l}\text { Most of the responders have completed vocational education } \\
(51.3 \%) \text {. The next most relevant group has engineering-level } \\
\text { education }(34.0 \%) \text {. The smallest groups of respondents are } \\
\text { university graduates }(3.5 \%) \text { and those without any professional } \\
\text { education }(1.7 \%) \text {. }\end{array}$ \\
\hline $\begin{array}{l}\text { Distribution of age of } \\
\text { respondents }\end{array}$ & $\begin{array}{l}\text { The largest group is } 31-40 \text { years old }(58 \%) \text {. The next largest } \\
\text { groups are } 41-50(23.5 \%) \text { and } 51-60 \text { years old }(22.6 \%) \text {. }\end{array}$ \\
\hline $\begin{array}{l}\text { Distribution of work } \\
\text { experience of } \\
\text { respondents }\end{array}$ & $\begin{array}{l}\text { Most of the respondents had over } 21 \text { years of work experience } \\
(30.4 \%) \text {. The next largest group had } 11-15 \text { years of work } \\
\text { experience }(23.5 \%) \text {. The smallest group had } 0-5 \text { years of work } \\
\text { experience }(9.6 \%) \text {. }\end{array}$ \\
\hline
\end{tabular}

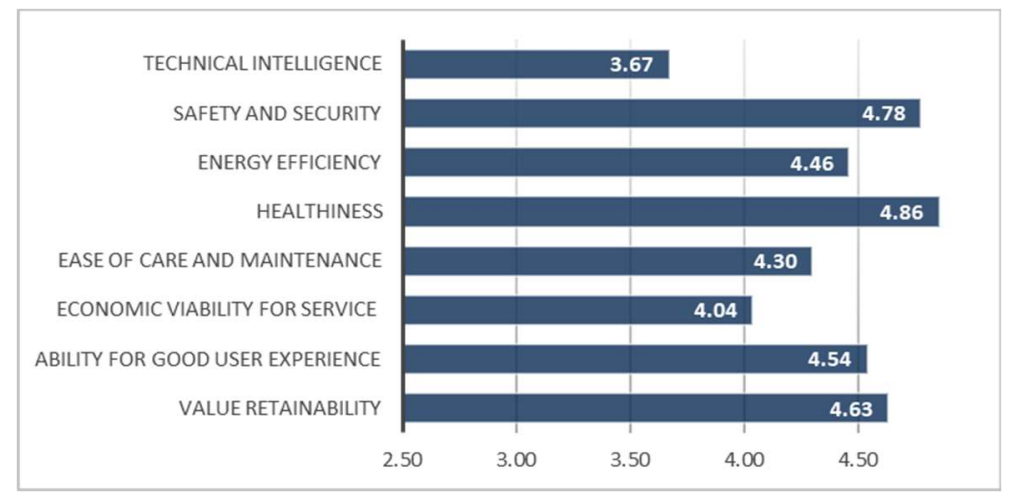

Figure 1 - Valuations of the features of a building in general.

In the second question, the respondents were asked to rank the ten most frequent property maintenance and service tasks (see Figure 2). Fault repairs emerged as the most important function (4.74/5) but receiving and managing alarms was almost equal (4.73/5). The third most important function was receiving and managing customer SRs (4.57/5), general care was fourth (4.50/5) and indoor conditions management was fifth (4.46/5). The sixth most important function was user satisfaction management (4.41/5). Respondents also found that calendar-based maintenance tasks (4.24/5), outdoor work (4.23/5) and controlling service and maintenance (4.23/5) had some importance. Energy use management and reporting $(4.15 / 5)$ were considered the least important items. 


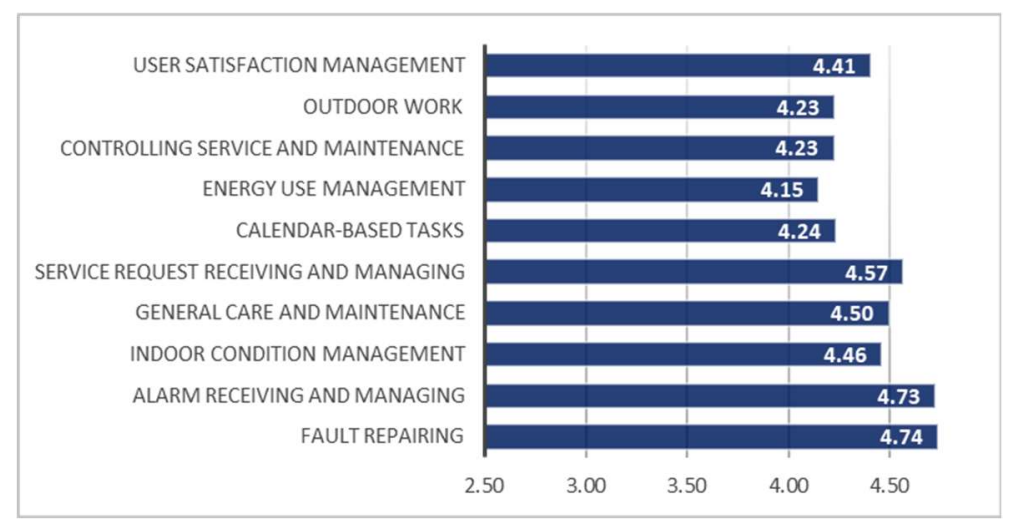

Figure 2 - Importance of property service tasks

Next we asked about the availability of the information required for the same maintenance and service tasks as used previously. Figure 3 presents the results of the third question. The best availability was for receiving and managing customer SRs (4.19/5), followed by calendar-based maintenance tasks (4.11/5) and receiving and managing alarms (4.10/5). The fourth best availability was for energy use and management (4.0/5) and the fifth was for controlling service and maintenance (3.89/5). Almost equal were outdoor work (3.87/5) and general care and maintenance $(3.86 / 5)$. The availability of information on fault repairing was the third poorest $(3.81 / 5)$. The weakest availability was for indoor conditions management $(3.78 / 5)$ and user satisfaction management (3.75/5).

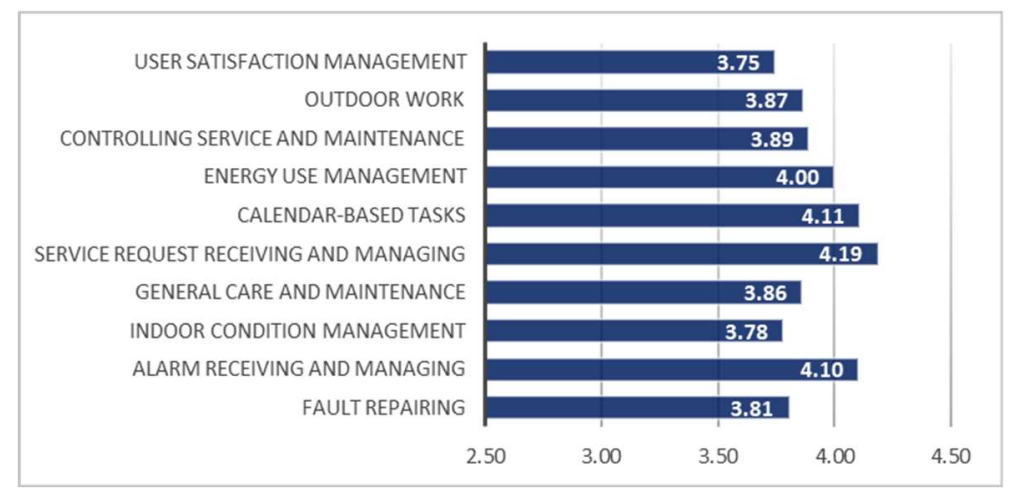

Figure 3 - Availability of information for certain service tasks.

About half of the respondents (45.7\%) considered the availability of information to generally be good. Nearly one fifth $(21.7 \%)$ found that information availability was very good, and about one fifth (19.1\%) considered it acceptable. Only 3.1\% thought that it was poor, and $1.0 \%$ considered it very poor. 
The fourth question was related to sources of information concerning day-to-day tasks and running the building given by various people or from a variety of sources. The respondents were asked to rank the importance of the information sources related to their own task areas (see Figure 4). The CMMS was reported to be the most important source of information (4.29/5). The second most important information source was the owner's customer SR management system (4.27/5), and the next two highest were colleagues or the support centre and the internet (both 4.14/5). The property manager ranked fifth $(4.07 / 5)$, paper documents sixth (3.91/5) and the energy management system (EMS) seventh (3.89/5). The importance of the property service company's IT system was estimated to be small (3.25/5). The owner's online repository was considered to be the least relevant source of information (3.05/5).

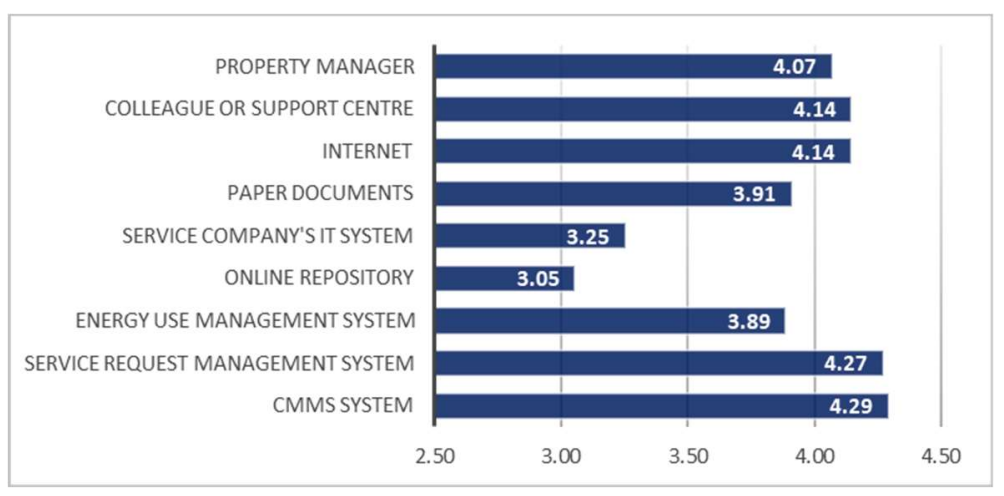

Figure 4 - Meaning on information sources

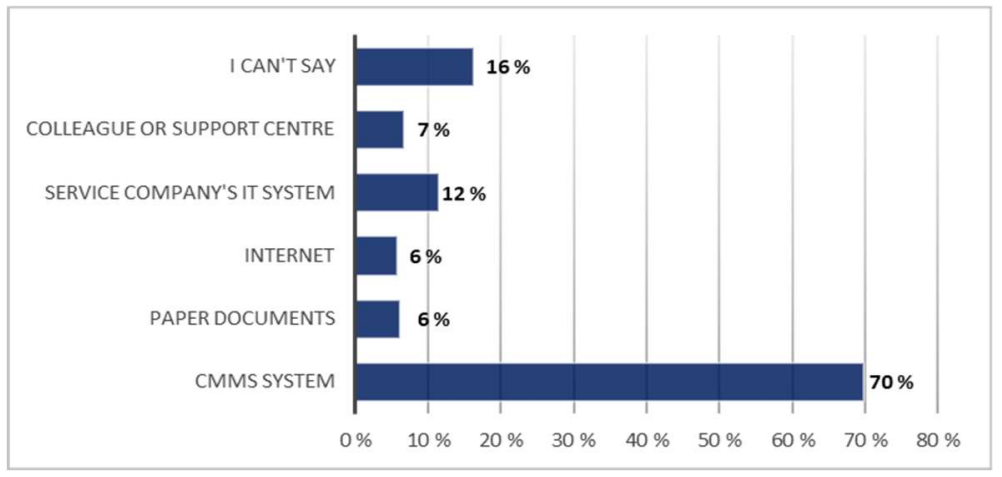

Figure 5 - First-used information sources.

Next, the first-used source of information was mapped when the respondents searched for information on the most essential tasks (see Figure 5). The CMMS was the most commonly used source of information, as $70 \%$ of respondents chose it as their first source. The property service company's IT system was the second most commonly used source (12\%) and a colleague or the service company's support centre came in third (7\%). Using the internet and 
paper documents as sources were seen as a last resort (both sources being chosen by $6 \%$ ). Unlike the other questions, the share of the 'I can't say' answers was significant (16\%).

Then the respondents were asked about their experience of using BIM over the last two years. The results reveal that $74 \%$ of respondents had not used BIM over the last two years. Only $2.49 \%$ had used BIM regularly (see Figure 6).

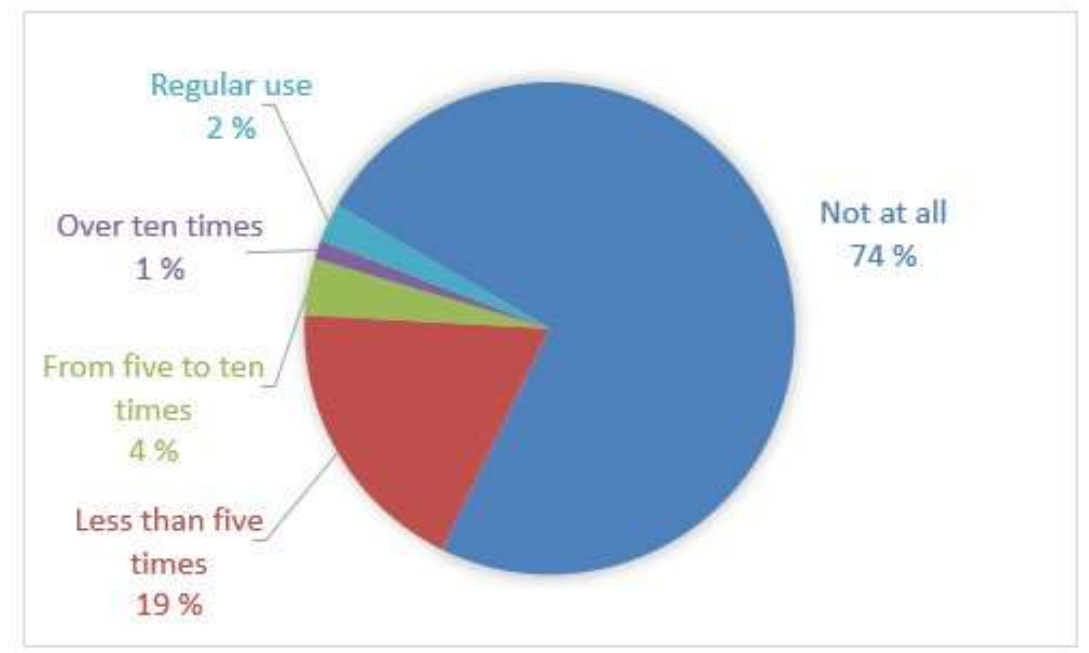

Figure 6 - BIM use over the last two years.

Figure 7 presents the most usual current reason for BIM use. BIM was mostly used for the planning of service and maintenance actions because $37.2 \%$ of the respondents used them for that purpose. The next most common use was identifying HVAC system operating areas $(32.6 \%)$ and controlling service and maintenance operations (30.2\%). The two lowest-ranked uses were using BIM to check care categories and design staff resources (both accounting for $2.3 \%$ ). Only those who had experience of using BIM (10\% of all respondents) answered this question.

The next question concerned the importance of BIM features (see Figure 8). Showing the operation areas of HVAC systems was the most important feature (4.30/5). Showing pipes, ducts and cable ladders (4.20/5) and showing dampers and shut-off valves (4.19/5) were next. Showing equipment to maintain was fourth (4.11/5), while showing technical details of equipment and showing the service and maintenance instructions (4.06/5) were fifth and sixth, respectively. The monitoring of emergency and hauling routes was ranked seventh (3.93/5), and identifying users' spaces came eighth (3.77/5). Showing the areas and volumes of the building was seen as the least important feature (3.49/5). Lastly, we asked about the importance of BIM for specific maintenance tasks. Figure 9 presents the results of this question. BIM was seen to be the most important for fault repairs $(4.06 / 5)$. The next highest importance was given to indoor conditions management (4.04/5). The next two most important items were receiving and managing customer SRs and receiving and managing alarms (both scoring 4.03/5). The fifth was general care and maintenance (3.91/5), and the 


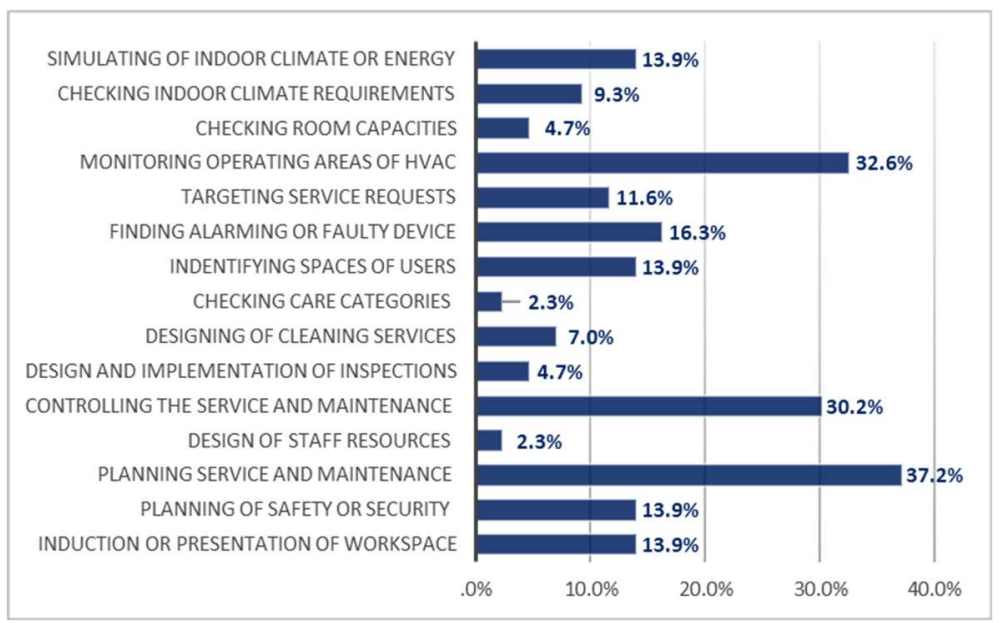

Figure 7 - Current BIM use purposes.

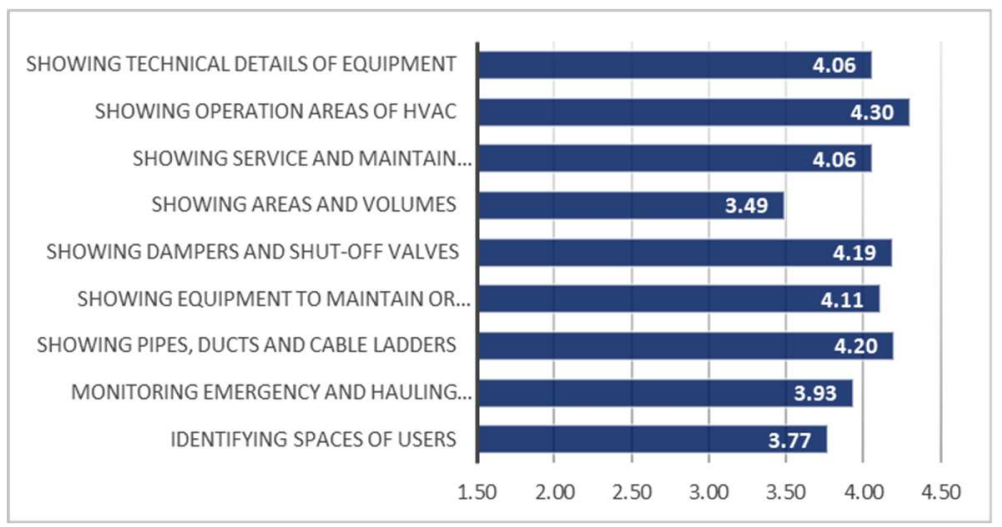

Figure 8 - Importance of BIM features.

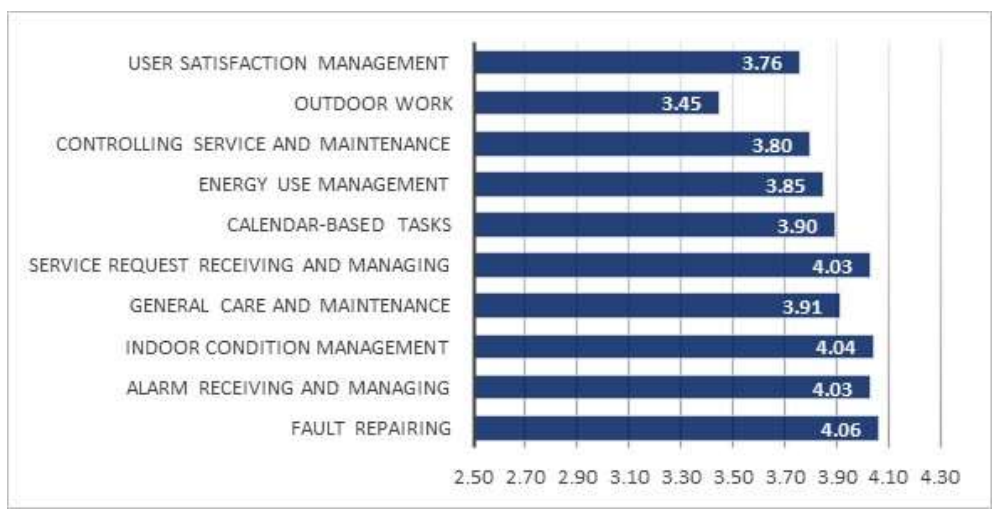

Figure 9 - The importance of BIM features for certain tasks. 
sixth was for calendar-based tasks (3.90/5). The seventh most important use was for energy use management (3.85/5). Controlling service and maintenance activities was the eighth most important use (3.80/5), and user satisfaction management was ninth (3.76/5). The least significant was seen to be outdoor work $(3.45 / 5)$.

\section{The textual comments}

The textual comments revealed that the current availability and level of information were insufficient for everyday FMO work. For example, the respondents said that more information was needed about materials, such as information about their surfaces. They also reported that tacit information is often lost, and the history of previous repairs is not available. It is known that the current systems enable history recording but, according to the comments, the feature is not widely used. The respondents also wanted more detailed customer feedback. They considered the building automation system as an important source of information, especially in exploring the history of indoor conditions.

Most of the respondents were not familiar with BIM. Therefore, many of the comments were irrelevant. For example, the most desired feature for BIM was the real-time monitoring of indoor conditions.

The respondents reminded us that the most important FMO task is to ensure the continuity of the user's actions in good conditions, without hampering the service work. They also emphasised that property maintenance was all too often criticised based on external factors, such as lawns or plants on the property, when the main emphasis of the work is on matters that remain unseen, such as indoor conditions.

In the comments, the role of a remote control room was considered significant. For example, the respondents said that the responsibility for the control of energy consumption had been transferred to remote control room specialists from the local service staff.

\section{The analysis of IFC files and the CMMS}

The purpose of comparing the content of the IFC files and the CMMS was to explore whether they included the same components and if the components were recognisable. According to the device lists of the CMMS, the most commonly maintained devices were control and automatic valves, fire dampers, automatic airflow control dampers, fans, pumps, replaceable filters, expansion vessels and different controllable tanks. A comparison was made on a perbuilding basis.

Table 2 indicates that the CMMS contains only one of the two automatic and control valves from the IFC files. Similarly, the CMMS only includes one third of the fire dampers and automatic airflow dampers. In turn, only $16 \%$ of the listed fans and $28 \%$ of the pumps of the CMMS were found in the IFC files. Only $12 \%$ of the replaceable filters and $52 \%$ of the expansion vessels and controllable tanks were presented in the IFC files.

The areas and volumes of the building were defined in 53\% of the studied buildings. This issue is not very important for service staff in their daily work, but it is crucial when using BIM as base data for other systems. For example, calculations on energy consumption, effective space use and rentals, as well as many simulations, require this sort of data.

Data on the spatial separation of the users was missing from all BIM files. In this context, this refers to the interfaces between different tenant-managed spaces in multi-user buildings 
and spaces rented to outsiders, in addition to owner-managed areas. The information about user organisations may not necessarily be available at the planning stage. However, the borderlines are essential to the service provider. The maintenance tasks can be different with different occupants, and emergency escapes may not be possible through other organisations' spaces.

Table 2 - Comparison of contents of CMMS and IFC file

\begin{tabular}{lll}
\hline Control and automatic valves & 824 & 1,538 \\
\hline Fire and automatic dampers & 665 & 2,273 \\
\hline Fans (incl. integrated) & 1,205 & 197 \\
\hline Pumps & 497 & 141 \\
\hline Replaceable filters & 476 & 55 \\
\hline Expansion vessels and tanks & 109 & 57 \\
\hline Total & 3,776 & 4,261 \\
\hline
\end{tabular}

Architectural space objects, which usually represents a cubicle accompanying the walls of a room, were defined in 53\% of the studied buildings. Space objects are needed when a device (e.g. a ventilation machine) is to be connected to a particular room. Additionally, space objects are required when visualising the conditions in the external UI. Lacking space objects in an IFC file is mainly due to defective definition in an IFC exporter. Many IFC exporters and importers are defective and limited, and require special care in their use.

The exits and hauling routes were also presented adequately in $53 \%$ of the studied buildings. In the other buildings, the information must be collected manually. This matters when planning an emergency exit as premises change and when heavy or large equipment needs to be moved.

None of the care and maintenance instructions were included or linked to any IFC files. This leads to the need to manually search for the information in other systems. In the studied portfolio, the task was complicated because the devices were described differently in BIM and the CMMS. Often, even the names were not the same.

The technical details of structures were presented in $67 \%$ of the studied buildings. This information is relevant to property maintenance when there is a need to replace or repair a damaged construction product. The information facilitates the selection of a replacement product and helps to evaluate repair methods.

Pipes, ducts and cable ladders were presented comprehensively. Service staff can use location and size information to plan repairs and to locate faulty components.

The equipment requiring maintenance according to the CMMS task list was only presented adequately in one building. The question is not always one of missing information; often it was that things were presented differently. For example, the MEP designer may use a packed object in an IFC file, while the CMMS author may unpack it as components that are to be 
maintained. Respectively, a CMMS author may state that only the main item of equipment is to be maintained while the designer creates all the components in an IFC file. In some buildings, only the mandatory information for creating an object was given, and all other fields were left blank. Also, building service technology equipment was often only defined as space reservation, and the design discipline was assigned as architectural.

The technical details of the building's technology devices were created in $93 \%$ of the studied buildings. Although comparability with the CMMS assignments was poor, the designers had provided a lot of technical information. That information is relevant to property service staff when replacing a damaged device with a new one.

Dampers and shut-off valves were presented in $87 \%$ of the studied buildings. This information is needed by property service staff when seeking a reason for a problem with indoor conditions or when a broken pipe or another reason for a water leak threatens to damage the building. The information is also useful when replacing or repairing a damaged component.

No HVAC operation areas were presented for any buildings. This information is needed by property service staff when seeking a reason for a problem with indoor conditions. It also facilitates planning changes to spaces when the capacity and operation area of a ventilation or air-cooling machine is seen from BIM.

Table 3 - Usable BIM features in most crucial FMO tasks.

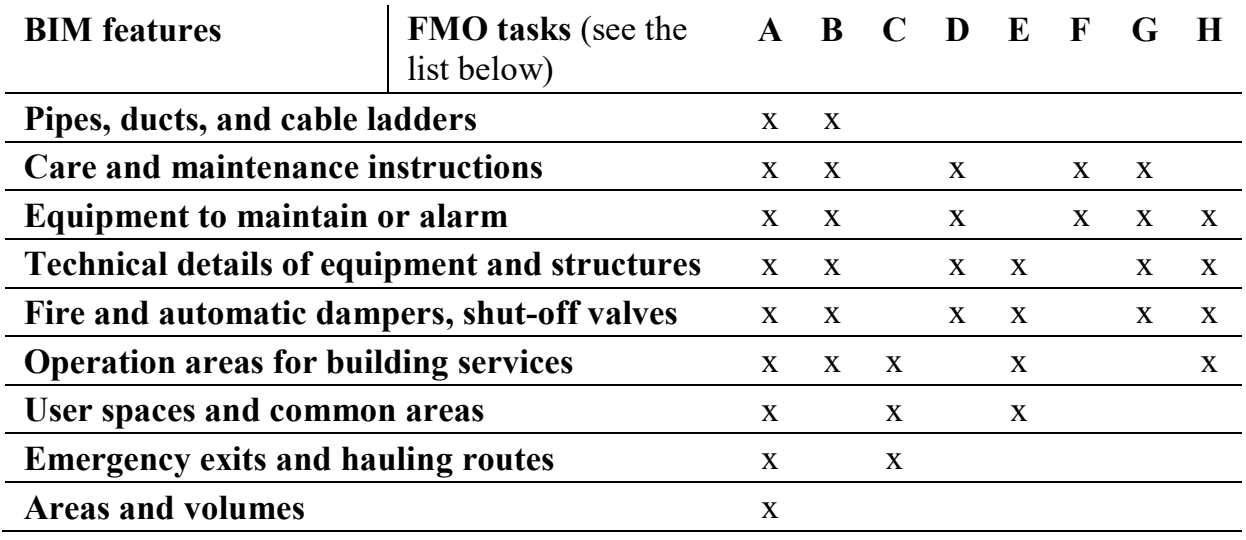

The numbers of FMO tasks:

A. General care and maintenance

B. Fault repair

C. User satisfaction

D. Calendar-based tasks

E. Service request managing

F. Outdoor care

G. Alarm receiving and managing

H. Energy management 
Table 3 shows which features of BIM are needed for specific FMO tasks. Table 3 only presents the priority needs and does not cover all the particular cases. It can be seen that general care and maintenance can take advantage of all the features. Fault repair operations may benefit from the top six features, which are comprised of technical data and information on the operation areas. The calendar-based tasks and receiving and managing alarms mostly require technical details and instructions, and user satisfaction management and maintenance control require information about the spaces in the building. Outdoor care would benefit from care and maintenance instructions and information on the devices that need to be maintained. The receiving and managing of service requests can take advantage of technical details and information about different areas of the building. Energy management could reap benefits from technical details and information about the operating areas of building service systems.

In summary, the visual appearance of BIM can be utilised in almost all use cases. For example, equipment that needs to be maintained or for which alarms need to be installed or monitored, the technical details of equipment and structures, fire and automatic air volume control dampers, and shut-off valves should always be presented. Only rare-use cases utilise areas and volumes, as well as information on pipes, ducts and cable ladders.

\section{DISCUSSION}

\section{Previous research}

Previous research has focused on using BIM-based visualisations on construction sites, for purposes such as construction safety planning and training [55] and production planning [56], as well as design review sessions [57, 58,59]. Additionally, BIM has previously been studied from the perspective of FM, and pilot projects have successfully integrated BIM with a CMMS. However, previous investigations have primarily concentrated on investigating IT using certain software and IT solutions. Instead, we studied use cases and preparedness for using BIM's visual features in FMO.

Previous efforts have not provided information on how the content of BIM, created in a practical construction project, meets the requirements of real-life service and maintenance. In this case study, we present the elaborated content for the introduction of BIM for FMO.

This investigation confirms previous findings that there is a need to expand BIM beyond the design and construction phases and to consider using it for facility maintenance activities. To benefit, the design for maintenance should be considered in the early design phase $[60,61]$. Previously, it has also been found that specific information requirements for building information models to support FM systems are needed [62]. The study also confirms an earlier finding that facility managers can benefit from the advantages of BIM to enhance managing the significant amount of information [63].

\section{Key findings on FMO tasks}

The results reveal that the service personnel found reactive tasks, such as fault repairing and receiving alarms, as the most important tasks. Proactive tasks are often seen to be useless routines. The values of the service personnel do not necessarily coincide with the values of the building owner. For example, the technical intelligence of a building was the least-valued feature, yet it is highly rated by the principal company. It can be concluded that the weak 
appreciation of proactive tasks correlates with the weak appreciation of the technical intelligence of a building.

Also, it was indicated that outdoor tasks are not adequately described in the CMMS. Because up to $52 \%$ of on-site time is used in outdoor activities [64], half of the maintenance work is carried out using incomplete instructions or general knowledge. According to the comments, the most experienced service staff primarily do their jobs without any IT systems. IT systems were only used when it was not possible to resolve the problem otherwise.

In contrast to preconceptions, energy management was a poorly appreciated task. The result seems to contradict the principal company's environmental objectives, which are highlighted in its Corporate Social Responsibility Report. The result is a consequence of the fact that the importance of energy management has declined in public debate. Respectively, the importance of indoor conditions and health of the building has increased. The significance of on-site energy management has also decreased because large service providers have shifted the primary responsibility for that to remote control rooms.

\section{The availability of information in daily tasks}

The results reveal that the availability of information is deficient in several FMO tasks. This is primarily due to the insufficient content of the CMMS. Figure 10 shows that the gap is the most extensive concerning fault repairs. The next most substantial gap is for the items receiving and managing alarms, indoor condition management, user satisfaction management and general care. The gap is only at an acceptable level for calendar tasks and energy management.

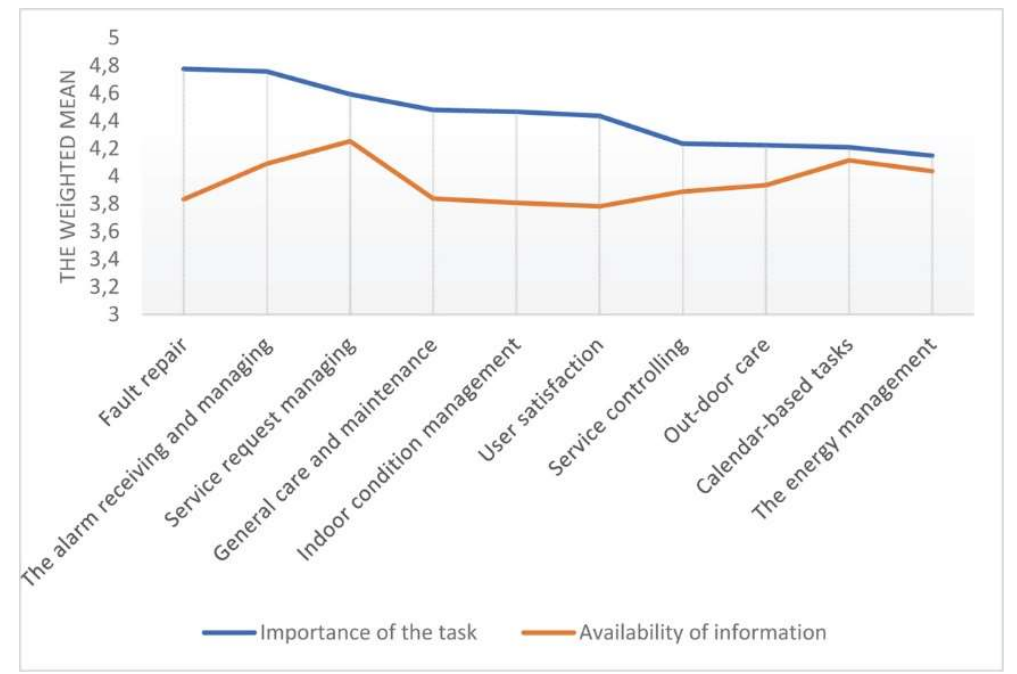

Figure 10 - The availability of information in relation to the importance of the task.

The traditional FM management systems, such as CMMSs, were seen by the respondents in this study as primary sources of information. Also, communication with other professionals was considered essential. A contradiction to this was found when asking respondents to 
evaluate the use of the internet as a source of information. The internet was seen to be the third most meaningful source of obtaining semantic information, but it was a last resort when we asked about the order of importance of information sources. This indicates that the information content of official sources that support the task were not considered adequate. It also shows that the information was deemed to eventually be found on the internet if it cannot be found elsewhere.

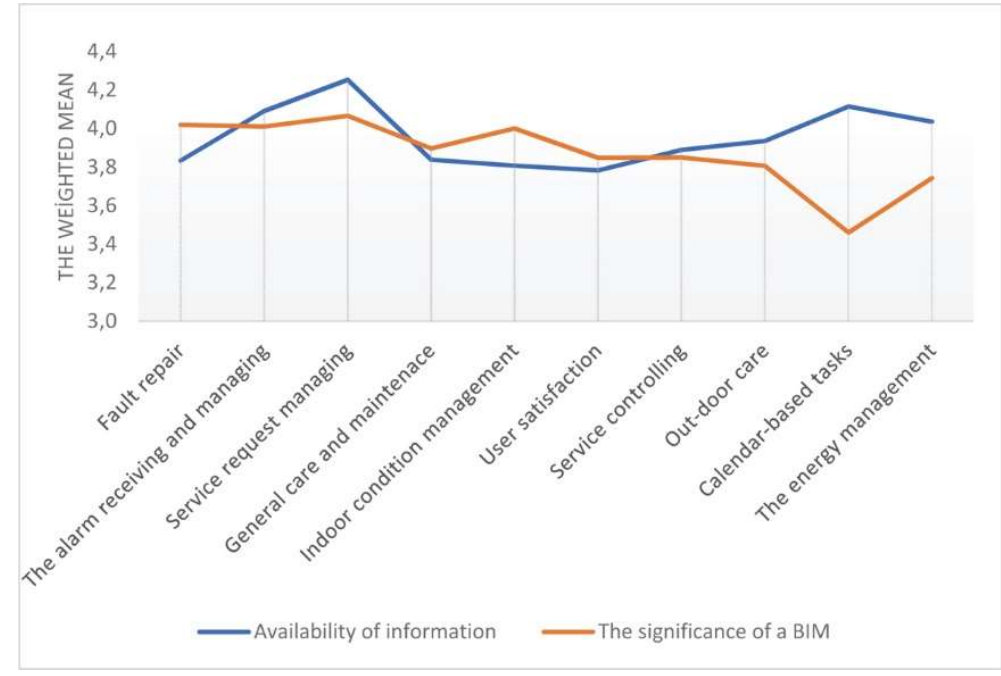

Figure 11 - The availability of information in relation to the significance of BIM.

The chart in Figure 11 shows the significance of BIM (orange polyline) and the availability of information (blue polyline) in the same diagram. The significance of BIM is evaluated to be higher than the availability of information for four tasks: (a) fault repairs, (b) general care, (c) indoor management and (d) user satisfaction management. That means that respondents expect the BIM to improve the availability of information specifically for these tasks.

Most of the service personnel are interested in BIM and are eager to use it in their daily work. However, at this time, BIM is little known. Three crucial reasons for this are: current BIM files do not contain the required information; BIM files are not available to the service personnel; and the property service company does not have the required visualisation tools. Additionally, BIM is often considered to be complicated among service staff.

The primary research question was successfully answered by presenting a new use case for BIM: an operations and maintenance model (OMM). The OMM is based on an as-built BIM, created and updated by the construction project planning team and enriched by maintenance professionals.

Figure 12 presents a flow chart for creating an OMM. The left side of the chart shows the construction stakeholders, and the right side shows the post-construction stakeholders. In the middle of the chart, BIM's lifespan is shown, starting with the design stage. The OMM is based on the as-built model, enriching it with additional information needed for maintenance. 
The recommended content of the OMM is presented in Annexe 1. The use cases of the owner, the workplace's service provider and the space users are given in Annexe 2.

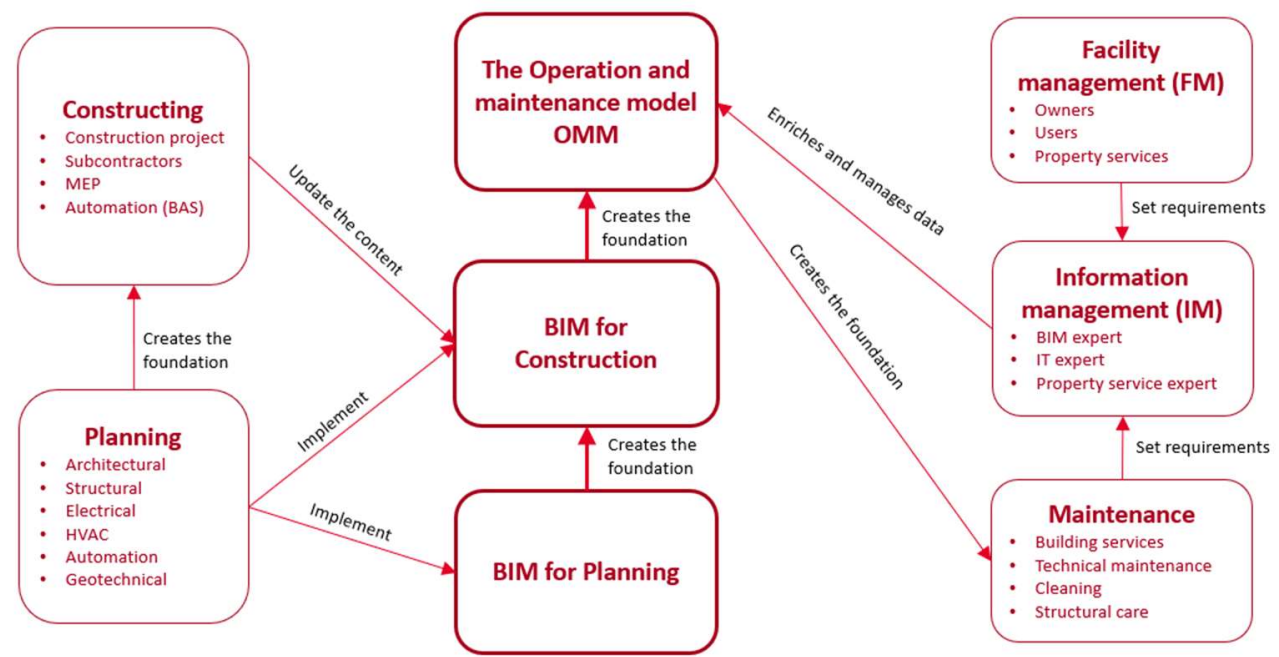

Figure 12 - The evolution of BIM

\section{CONCLUSIONS}

Existing building information models cannot close the information gap for property maintenance as such, but they have significant potential. Most devices and components are named in an informal way, which hampers their recognition and discovery. CMMS maintenance tasks are difficult to connect to devices. Ducts, pipes and cable trays are mainly well displayed, but the operation areas of HVAC systems are not usually shown. The technical detail coverage for devices also varies greatly.

The results show that graphical presentation is the greatest strength of BIM. The service personnel require detailed information on the operational areas of the building service systems and the devices they need to maintain. Additionally, devices that can affect indoor conditions must be shown, as well as the components that must be detected in fault correction cases; and general information on different routes and detailed information about spaces are required.

The results of the empirical research show that the required content is incomplete or missing, despite long-used design methods, advanced tools and detailed instructions. One of the most serious deficiencies is the lack of a connection between BIM and CMMS. Changing the situation requires a complete renewal of the design process.

Based on results, it is possible to create IER guidelines for the principal company, as well as for the entire real estate industry. In creating IER, ISO 19650 and COBie standards must also be followed. After introducing the IER and using the right design tools, a significant leap could be taken in the exploitation of digital data in FM. Additionally, maintenance experts must be assigned to the project at an early stage in order to determine how the building will 
be maintained. This will ensure sufficient information content in the OMM and the easy maintenance of technical systems and structures.

The principal company's drive to adopt smart buildings and promote the introduction of a digital twin of buildings requires the BIM process to be reformed. The current as-built material as such is not sufficient - it needs to be significantly developed. The property service company's capabilities must also be evolved before the benefits of digital capital can be reaped.

\section{References}

[1] COBIM2012, Common BIM Requirements of Finland Series 12 Use of models in facility management, Rakennustieto Oy, Finland, p. 5.

[2] Xin, Q. (2011), "Building information modelling (BIM) adoption of construction project management based on Hubei Jinzhou bus terminal case", in 2011 International Conference on Business Computing and Global Informatization, pp. 282-284.

[3] Han, N., Yue, Z.F. and Lu, Y.F. (2012), "Collision detection of building facility pipes and ducts based on BIM technology", Advanced Material Research, Vol. 346, pp. 312317.

[4] Wang, Y., Wang, X., Wang, J., Yung, P. and Jun, G. (2013), "Engagement of facilities management in design stage through BIM: Framework and a case study", Advances in Civil Engineering, Vol. 8.

[5] Hardin, B, and McCool, D. (2015), BIM and Construction Management, Proven Tools, Methods, and Workflows, Wiley Publishing, IN, US, p. 12.

[6] Kensek, K. (2015), "BIM guidelines inform facilities management databases: A case study over time", School of Architecture, University of Southern California, LA, US, p. 904.

[7] National BIM Standard-United States NBIMS-US ${ }^{\text {TM }}$ (2015), National Institute of Building Sciences, 1090 Vermont Avenue, NW, Suite 700 Washington, DC US, p. 1.

[8] Krygiel, E. and Nies, B. (2008), Green BIM: Successful Sustainable Design with Building Information Modelling, John Wiley \& Sons, US, p. 26.

[9] Gurgun, A., Koc, K., Atabay, S. (2021). Impacts of Using Building Information Modeling (BIM) in Sustainable Green Building Projects (in Turkish). Teknik Dergi. 33. https://doi.org/10.18400/tekderg. 715574

[10] Li Juan, C. and Hanbin, L. (2014), “A BIM-based construction quality management model and its applications", School of Civil Engineering \& Mechanics, Huazhong University of Science \& Technology, Wuhan 430074, China, p. 1.

[11] Eastman, C., Teicholz, P., Sacks, R. and Liston, K. (2011), BIM Handbook: A Guide to Building Information Modelling for Owners, Managers, Designers, Engineers and Contractors, second ed., Wiley US, p. 1. 
[12] Fountain, J, and Langar, S, (2018), "Building information modelling (BIM) outsourcing among general contractors", Automation in Construction, Vol. 95, pp. 107-117.

[13] Azhar, S., Khalfan, M. and Maqsood, T. (2015), "Building information modelling (BIM): Now and beyond", Australasian Journal of Construction Economics and Building, Vol. 12 No. 4, pp. 15-28.

[14] Yoon, S., Park, N. and Choi J. (2009), "A BIM-based design method for energyefficient building", in Proceedings of the 2009 Fifth International Joint Conference, pp. 376-381.

[15] Pittard, S. and Sell, P. (2016), BIM and Quantity Surveying, Routledge, ISBN: 978-0415-87042-9

[16] McArthur, J.J., Shahbazi, N., Fok, R., Raghubar, C., Bortoluzzi, B. and An, A. (2018), "Machine learning and BIM visualization for maintenance issue classification and enhanced data collection", Advanced Engineering Informatics, Vol. 38., pp. 101-112.

[17] Chen, W., Chen, K., Cheng, J.C.P., Wang, Q. and Gan, V.J.L. (2018), "BIM-based framework for automatic scheduling of facility maintenance work orders", Automation in Construction, Vol. 91, pp. 15-30.

[18] Pärn E.A., Edwards D.J. and Sing, M.C.P. (2017), “The building information modelling trajectory in facilities management: A review", Automation in Construction, Vol. 75, pp. 45-55.

[19] Ustinovičius, L., Popov, V., Čepurnaitè, J., Vilutienè, T., Samofalov, M. and Miedziałowski, C. (2018), "BIM-based process management model for building design and refurbishment", Archives of Civil and Mechanical Engineering, Vol. 18 No. 4, pp. 1136-1149. https://doi.org/10.1016/j.acme.2018.02.004

[20] Heaton, J., Parlikad, A.K. and Schooling, J. (2019), "Design and development of BIM models to support operations and maintenance", Computers in Industry, Vol. 111, pp. 172-186. https://doi.org/10.1016/j.compind.2019.08.001

[21] ISO 16739:2013 Industry Foundation Classes (IFC) for data sharing in the construction and facility management industries. ISO International Organization for Standardization, 2013.

[22] East, W. (2009) BIM Enables Success on WTC Mega Project. Journal of Building Information Modeling, Fall 2019, pp. 18-20.

[23] East, W., Carrasquillo-Mangual, M. (2013) The COBie Guide: A commentary to the NBIMS-US standard. https://www.bimpedia.eu/static/nodes/1010/COBie_Guide_-_Public_Release_3.pdf

[24] Alexander, K. (2013), Facilities Management: Theory and Practice, Routledge, New York.

[25] Atkin, B. and Brooks, A. (2009), Total Facilities Management, third ed., Wiley and Blackwell, Hong Kong.

[26] Barrett, P. and Baldry, D. (2009), Facilities Management: Towards Best Practice, Blackwell Science, Oxford, USA. 
[27] Lepkova, N. and Uselis, R. (2013), "Development of a quality criteria system for facilities management services in Lithuania", in 11th International Conference on Modern Building Materials, Structures and Techniques, MBMST, p. 2.

[28] ISO Standard ISO 41011:2017 Facility Management - Part 1: Terms and definitions

[29] GSA (2011) BIM Guide for Facility Management, U.S. General Services Administration, the National 3D-4D-BIM Program, [Cited 2018, 30.1.2018] Available at: https://www.gsa.gov/real-estate/design-construction/3d4d-building-informationmodeling

[30] ISO 19650-1:2018 Organization and digitization of information about buildings and civil engineering works, including building information modelling (BIM) Information management using building information modelling — Part 1: Concepts and principles.

[31] UK BIM Alliance (2019). Information management according to BS EN ISO 19650. Guidance Part 1: Concepts.

[32] Kim, K., Kim, H., Kim, W., Kim, C., Kim, J., Yu, Y. (2018). "Integration of IFC objects and facility management work information using Semantic Web", Automation in Construction, Vol. 87, pp. 173-187.

[33] Chen, L., Shi, P., Tang, Q., Liu, W., Wu, Q. (2020). "Development and application of a specification-compliant highway tunnel facility management system based on BIM", Tunnelling and Underground Space Technology, Vol. 97, pp. 103262.

[34] Motawa, I. and Almarshad, A. (2013), “A knowledge-based BIM system for building maintenance”, Automation in Construction, Vol. 29, pp. 173-182.

[35] Halmetoja, E. (2019), "The conditions data model supporting building information models in facility management", Facilities, https://doi.org/10.1108/F-11-2017-0112

[36] Kang, T.-W. and Choi, H.-S. (2015), "BIM perspective definition metadata for interworking facility management data", Advanced Engineering Informatics, Vol. 29, pp. 958-970.

[37] Aziz, N.D., Nawawi, A.H. and Ariff, N.R.M. (2016), "Building information modelling (BIM) in facilities management: Opportunities to be considered by facility managers", Procedia - Social and Behavioural Sciences, Vol. 234, pp. 353362.

[38] Pishdad-Bozorgi, P., Gao, X., Eastman, C. and Self, A.P. (2018), "Planning and developing facility management-enabled building information model (FM-enabled BIM)", Automation in Construction, Vol. 87, pp. 22-38.

[39] Gao, X. and Pishdad-Bozorgi, P. (2019), "BIM-enabled facilities operation and maintenance: A review", Advanced Engineering Informatics, Vol. 39, pp. 227-247. https://doi.org/10.1016/j.aei.2019.01.005

[40] Wong, J. K. W., Ge, J., \& He, S. X. (2018). Digitisation in facilities management: A literature review and future research directions. Automation in Construction, Vol. 92, pp. 312-326. 
[41] Araszkiewicz, K. (2017). Digital technologies in Facility Management-the state of practice and research challenges. Procedia Engineering, 196, 1034-1042.

[42] Cavka, H.B., Staub-French, S. and Poirier, E.A. (2017), "Developing owner information requirements for BIM-enabled project delivery and asset management", Automation in Construction, Vol. 83, pp. 169-183.

[43] Wright, K.B. (2005), "Researching internet-based populations: Advantages and disadvantages of online survey research, online questionnaire authoring software packages, and web survey services", Journal of Computer-Mediated Communication, Vol. $10 \quad$ No. $3, \quad$ available at: https://academic.oup.com/jcmc/article/10/3/JCMC1034/4614509 (accessed 18 Jan 2020).

[44] Garton, L., Haythornthwaite, C. and Wellman, B. (1999), "Studying on-line social networks", in Jones, S. (Ed.), Doing Internet Research: Critical Issues and Methods for Examining the Net, Sage, Thousand Oaks, CA,. pp. 75-105.

[45] Wellman, B. (1997), "An electronic group is virtually a social network", in Kiesler, S. (Ed.), Culture of the Internet, Lawrence Erlbaum, Mahwah, NJ. pp. 179-205.

[46] Hirsijärvi, S., Remes, P. and Sajavaara, P. (2010), Tutki ja kirjoita, Tammi. Helsinki, p. 195.

[47] Bharadwaj A.S. (2000), "A resource-based perspective on information technology capability and firm performance: An empirical investigation”, MIS Quart., Vol. 24 No. 1, pp. 169-196.

[48] ISO Standard ISO 41011:2017 Facility Management - Part 7: Guidelines for Performance Benchmarking.

[49] Joshi, A., Kale, S., Chandel, S. and Pal, D.K. (2015), "Likert scale: Explored and explained", British Journal of Applied Science \& Technology, Vol. 7 No. 4, pp. 396403.

[50] Keil, M., Mann, J. and Arun, R. (2000), "Why software projects escalate: An empirical analysis and test of four theoretical models", MIS Quart., Vol. 24 No. 4, pp. 631-664.

[51] Ghauri, P.N. and Gronhaug K. (2002), Research Methods in Business Studies, Financial Times Ltd, New York, USA.

[52] Burns, R. (2000), Introduction to Research Methods, Sage, London.

[53] COBIM2012 Common BIM Requirements of Finland Series 4 MEP Design, Rakennustieto Oy, Finland, p. 9.

[54] Ustinovičius, L., Peckienè; A. and Popov, V. (2017), "A model for spatial planning of site and building using BIM methodology", Journal of Civil Engineering and $\begin{array}{llllll}\text { Management, } & \text { Vol. } & 23 & \text { No. } & 2, & \text { pp. }\end{array}$ https://doi.org/10.3846/13923730.2016.1247748

[55] Hafsia, M., Monacelli, E., Martin, H. (2018). Virtual Reality Simulator for Construction workers. In Proceedings of the Virtual Reality International Conference (VRIC 18), Laval, France. 
[56] Muhammad, A. A., Yitmen, I., Alizadehsalehi, S., Celik, T. (2019). Adoption of Virtual Reality (VR) for Site Layout Optimization of Construction Projects. Teknik Dergi, $31(2)$.

[57] Roupé, M., Johansson, M., Viklund Tallgren, M., Jörnebrant, F., Tomsa, P. (2016). Immersive visualization of Building Information Models. In: Living Systems and Micro-Utopias: Towards Continuous Designing (Proceedings of CAADRIA 2016), 21, pp. 673-682.

[58] Zaker, R., Coloma, E. (2018). Virtual reality-integrated workflow in BIM-enabled projects collaboration and design review: a case study. Visualization in Engineering, $6(1), 4$.

[59] Wolfartsberger, J. (2019). Analyzing the potential of Virtual Reality for engineering design review. Automation in Construction, 104, pp. 27-37.

[60] Liu, R. and Issa, R.R.A. (2013) "BIM for Facility Management: Design for Maintainability with BIM Tools." The 30th International Symposium on Automation and Robotics in Construction and Mining, Montreal, Canada. https://doi.org/10.22260/ISARC2013/0035

[61] Ghosh, A., Chasey, A.D., Mergenschroer, M. (2015) in Building information modeling: applications and practices, R. R. A. Issa and S. Olbina, Eds., ed: American Society of Civil Engineers, 2015.

[62] Matarneh S.T., Danso-Amoako, M.O., Al-Bizri, S., Gaterell, M., Matarneh, R.T. (2020), "BIM for FM: Developing information requirements to support facilities management systems", Facilities, Vol. 38 No. 5/6, pp. 378-394. https://doi.org/10.1108/F-07-2018-0084

[63] Naghshbandi, S. (2016) "BIM for Facility Management: Challenges and Research Gaps.” Civil Engineering Journal, Vol. 2, No. 12, December 2016.

[64] Kangasluoma, M., Jaatinen, A., Kaivanto, K., Kortelampi, A., Käpymäki, T., Fränti, H., Peltonen, K., Suomäki, J., Hännikäinen, J., Vepsäläinen, S., Tuomivaara, O., Väyrynen, L. (2018), Handbook of Property Maintenance, Kiinteistöalan Kustannus Oy, Helsinki, Finland, pp. 336-351. 


\section{ANNEXE 1.}

Lists $1 \mathrm{a}$ and $1 \mathrm{~b}$ include the visual information content of the OMM. These lists are based on responses to the online survey's Question 8. Lists $2 \mathrm{a}$ and $2 \mathrm{~b}$ are based on the content of the studied IFC MEP files, CMMS device lists and maintenance task lists.

List 1a. The indispensable information content of the OMM:

1. The operation areas of building service systems (HVAC)

2. Pipes, ducts and cable ladders

3. Dampers and shut-off and automatic valves

4. Equipment to maintain or alarm

5. Technical details of equipment to maintain

6. Service and maintenance instructions

List 1b. Optional information content of the OMM:

7. Escape and hauling routes

8. User-specific spaces, shared spaces and boundaries between spaces

9. Areas and volumes

List 2a. Devices to present in the OMM:

1. Electric distribution boards and transformers

2. Safety and emergency lighting distribution boards and luminaires

3. Fire alarm panels and fire detection devices

4. Fixed luminaires

5. Elevators, hoists and escalators

6. Uninterruptible power suppliers (UPS), generators and other power suppliers

7. Heat distribution units, heat transmitters, pumps, tanks and piping

8. Heating radiators and other heating terminals

9. Water system pipelines, pumps, tanks, transmitters, reservoirs, separators and filters

10. Water fittings and basins

11. Air conditioning machines, closing dampers, filters, radiators, heat recovery (HR) equipment and ducts

12. Air conditioning terminals, grease filters and fume hoods and cubicles

13. Cooling machines and compressors, radiators, convectors, steamers and condensers

14. Firefighting pumps, valves, installations and piping

15. Compressed air compressors, tanks, coolers, dryers, filters and piping

16. Building automation sensors

List 2b. Obligatory device details in the OMM:

1. Device type and use purpose

2. Manufacturer and/or vendor

3. Year of manufacture and installation

4. Key operating values

5. Service periods and instructions (text, attachment or URI)

6. Maintenance periods and measures (text, attachment or URI) 


\section{ANNEXE 2.}

Besides the property maintenance operator, the building owner and building users can also utilise the OMM. The vendors of workplace services, such as cleaning and catering vendors, can also benefit from the OMM.

1. The owner's use cases for OMM

The shapes, spaces and other details can be visualised by the OMM. The following opportunities for a building owner are detected, based on visual information:

1. Illustrating the building's special features

2. Identifying structural opportunities for space and purpose changes

3. Identifying the building service system's opportunities from the rebuilding perspective

4. Identifying the building service system's opportunities from the property servicing tendering perspective

5. Evacuation safety review and planning

7. Access control planning

8. Presenting space arrangements to users

9. Illustrating the interfaces and dimensions of the different users' spaces

2. The workplace service's use cases for the OMM

Some of workplace services can utilise the technical information and some the visual information. The following opportunities are detected:

1. Visualising and identifying office equipment

2. Verifying the areas to be cleaned and maintained

3. Identifying the boundaries between different users

4. Ensuring transportation routes

5. Viewing maintenance classes and surface materials

6. Defining the operating areas of security services

7. Orientating service personnel

3. The user's use cases for the OMM

The following are some of the building operation uses of the OMM, based on visual information:

1. Verifying the use purpose of rooms

2. Workstation and furniture planning

3. Identifying the locations and equipment under one's own care

4. Verifying the boundaries between different spaces

5. Service request positioning

6. Evacuation safety and access control planning

7. Employee induction to facility safety and security 
